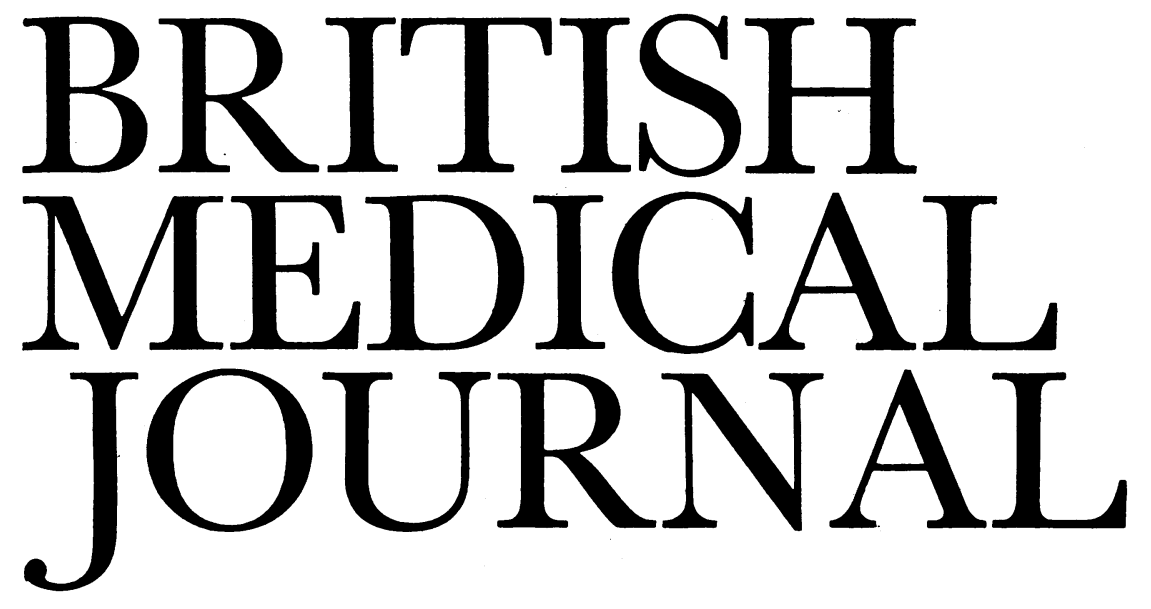

LONDON, SATURDAY 14 APRIL 1979

\title{
Coronary artery spasm
}

As one controversy is settled in coronary artery disease, another replaces it, for deeper study is apt to show how complex are even apparently simple problems. The mechanism of atheroma is still in debate, and there is no agreement whether in fatal myocardial infarction the thrombus found in the artery precedes and causes the acute ischaemia or is a consequence of it. ${ }^{12}$

Infarction may occur without thrombotic occlusion, as was shown 40 years ago. ${ }^{3}$ Once the importance of the collateral circulation became apparent its presence was used to explain how coronary occlusion may frequently occur without infarction or even without symptoms. ${ }^{45}$ In all of these earlier discussions the theme of coronary spasm lurked in the background and sometimes appeared in the open. ${ }^{3}$ Even in 1910 William Osler" had speculated on "a perverted internal secretion which favours spasm of the arteries," and had suggested that spasm or narrowing of a coronary artery or even one branch could modify the heart's action. But the decisive landmark was the description in 1960 by Prinzmetal et $a l^{7}$ of what came to be known as Prinzmetal's or "variant" angina: the occurrence of bouts of pain in a patient at rest, often cyclical, often associated with arrhythmias, and characterised not by ST depression (as seen in exertional angina) but by transient ST elevation. Patients who died were found to have considerable atheromatous stenosis of a major coronary trunk, and their angina at rest was attributed to a temporary increase in tone in the diseased vessel.

In the 10 years after Sones $^{8}$ introduced the technique of coronary angiography there were only a few sporadic reports of coronary spasm. With hindsight, this may be explained by misinterpretation of angiograms, the use of prophylactic vasodilators before catheterisation of the coronary ostia, and by less bold investigation than was adopted later. Certainly since 1972 examples of coronary spasm have become abundant and the evidence has been critically reviewed. ${ }^{9-11}$ True, spasm can be shown only when the artery is catheterised and injected with contrast medium, so that strictly "spontaneous" spasm cannot be proved visually. Nevertheless, the weight of probability in favour of spasm occurring without catheterisation is now so great that the hypothesis must be taken as proved. ${ }^{10}$ This is in no small measure due to the observations of Maseri et $a l^{12}$ at Pisa, who recently described ${ }^{13}$ the clinical course of
187 patients with angina at rest, 37 of whom had infarction. In eight patients various combinations of haemodynamic monitoring, radioactive-thallium scintigraphy, and coronary angiography were performed during episodes of pain which culminated in infarction. Reversible defects of perfusion were shown by scintigraphy, and reversible spasm at angiography. The onset of infarction was indistinguishable from the earlier attacks of angina, and the authors' conclusion seems irrefutable: in some patients spasm may precipitate infarction.

Prinzmetal's original concept that spasm occurred only in diseased vessels has had to be modified, for many patients with variant angina show no atheroma on angiography. ${ }^{14} 15$ Indeed, finding healthy arteries in patients with angina (even with abnormal electrocardiograms) is a common experience for every cardiologist, ${ }^{16}$ and most will have seen patients with proved infarction whose arteries seemed equally normal. ${ }^{17}$ The most favoured explanation has been embolism with recanalisation, ${ }^{18}$ but spasm must be considered as an alternative. Since it is in the nature of arteries to contract, from time to time an excessive and unphysiological increase in tone, localised or diffuse, might be expected to occur in both healthy and atheromatous arteries. This is the most plausible explanation of angina occurring in a patient, lying quietly in bed, who shows no change in heart rate or blood pressure. What remains to be explained is the mechanism. Lange et al ${ }^{19}$ have told the alarming story of angina and infarction precipitated by withdrawal of industrial exposure to nitrates, but that was a special case. An external stimulus such as cold may be a factor, ${ }^{20}$ but a more profitable line of inquiry may be a search for some intrinsic factor related to autonomic control $^{21}$ or to the products of platelet disintegration ${ }^{22}$ where Osler's perverted internal secretion may prove an inspired guess.

We may, then, accept coronary spasm causing pain in most patients with variant angina, and as a possible factor in some with conventional angina. Almost certainly spasm is the immediate cause of infarction in some patients with diseased arteries, and it has been demonstrated during the first six hours after the onset of symptoms, ${ }^{23}$ where prompt vasodilatation may be more effective than other measures aimed at limiting the size of the infarct. ${ }^{24}$ Spasm has not yet been proved to cause infarction in persons with normal arteries, 
except possibly on withdrawal from industrial exposure to nitrates. The chief implication for treatment is that betaadrenergic blockers remain a logical prophylactic against both exertional and emotional angina, but that vasodilators should have first place whenever there appears to be an unexplained reduction of oxygen delivery to the myocardium rather than an increased demand.

1 Erhardt, L R, Lundman, T, and Mellstedt, H, Lancet, 1973, 1, 387.

2 Chandler, A B, et al, American fournal of Cardiology, 1974, 34, 823.

3 Friedberg, C K, and Horn, H, fournal of the American Medical Association, $1939,112,1675$.

4 Blumgart, H L, Schlesinger, M J, and Zoll, P M, Fournal of the American Medical Association, 1941, 116, 91.

${ }^{5}$ Miller, R D, Burchell, H B, and Edwards, J E, Archives of Internal Medicine, 1951, 88, 597.

6 Osler, W, Lancet, 1910, 1, 839.

7 Prinzmetal, M, et al, fournal of the American Medical Association, 1960, 174, 1794.

8 Sones, F M, and Shirey, E K, Modern Concepts of Cardiovascular Disease, $1962,31,735$.

o Gensini, G G, Chest, 1975, 68, 709.

${ }^{10}$ Meller, J, Pickard, A, and Dack, S, American fournal of Cardiology, 1976, 37, 938.

11 Hillis, L D, and Braunwald, E B, New England fournal of Medicine, 1978, 299, 695.

12 Maseri, A, et al, Lancet, 1977, 1, 713.

13 Maseri, A, et al, New England fournal of Medicine, 1978, 299, 1271.

14 Selzer, A, et al, New England fournal of Medicine, 1976, 295, 1343.

${ }_{15}$ Higgins, C B, et al, American fournal of Cardiology, 1976, 37, 831.

16 Bemiller, C R, Pepine, C J, and Rogers, A K, Circulation, 1973, 47, 36.

${ }^{17} \mathrm{Khan}, \mathrm{A}$ H, and Haywood, L J, New England fournal of Medicine, 1974, 291, 427.

18 Arnett, E N, and Roberts, W C, Circulation, 1976, 53, 395.

19 Lange, R L, et al, Circulation, 1972, 46, 666.

${ }^{20}$ Mudge, G, et al, New England fournal of Medicine, 1976, 295, 1333.

21 Yasue, H, et al, Circulation, 1974, 50, 534.

22 Needleman, P, Kulkarni, P S, and Raz, A, Science, 1977, 195, 409.

${ }^{23}$ Oliva, P B, and Breckinridge, J C, Circulation, 1977, 56, 366.

${ }^{24}$ Hellstrom, H R, American Heart fournal, 1975, 90, 545.

\section{Choice of treatment in operable lung cancer}

Older patients with operable lung cancer may prefer the "near certainty" of a period of freedom from disease offered by radiotherapy to the riskier prospect of a possible cure by surgery with its small but definite chance of immediate death. That was the conclusion of a recent American study ${ }^{1}$ (based on only 14 patients) that assessed each individual's willingness to take or avoid the risk of death related to surgery, and the span of life he would reasonably expect. Most of the patients (mean age 67) were not inclined to accept the unavoidable risks of surgery and would have settled for the two to three more years of life offered by treatment with radiotherapy.

Of 100 patients who develop lung cancer fewer than 10 will live for five years. Eighty will have inoperable disease at diagnosis, and most of these will die within three years. Of the 20 patients with localised disease, most will have an operation, and about six of these will survive five years. These gloomy statistics have not changed over the last 30 years, despite many attempts at earlier diagnosis, and the five-year survival of resectable lung cancer remains at roughly $30 \%{ }^{2-4}$ During this period, however, the operative mortality rate has fallen, though it remains greatest in the elderly, and is worse after pneumonectomy than after lobectomy. While radiotherapy has no associated mortality it gives at best results that are marginally less effective than surgery in patients with operable tumours, and often the results are considerably worse. ${ }^{5}$

There are still considerable difficulties in deciding which patients should be offered surgery as the most effective long-term treatment. Many of them have chronic lung disease, and we still have no simple way of predicting postoperative pulmonary function from preoperative data. ${ }^{\circ}$ The level of physical activity that will be possible postoperatively is a matter of clinical judgment in each individual case.

By the time lung cancer causes symptoms it has passed through most of its natural life span, and in many cases it will have metastasised. Radionuclide scanning of brain, bone, and liver has added some refinement to the detection of metastases, but the yield is low in patients with no symptoms other than those directly referable to the primary tumour. ${ }^{7}$ Surgeons are still faced with advising operation to patients whom they know must be likely to have occult metastases. An important factor (not considered in the American study of risk evaluation) is the difference in growth rates of individual tumours. A recent comparison of the results of surgery and of conservative management of tumours presenting as peripheral solitary lesions within the lung (often discovered only at routine radiological screening) showed no benefit in terms of survival after surgical resection. ${ }^{2}$ The rate of growth, or the doubling time, for a tumour may be the most important single determinant of survival. ${ }^{8}$ While oat-cell carcinomas have doubling times of $\mathbf{3 0}$ days, squamous carcinomas and adenocarcinomas. take much longer-about 170 days for adenocarcinoma. ${ }^{9}$ The patients who survive longest-whether they have had surgery or not-are probably those with tumours with the slowest growth rates.

The physician or surgeon trying to decide whether he should offer surgery as a curative treatment still has to make his decision without all the facts he would like to have. Many patients can be excluded on the grounds of age alone, especially if their general health is poor or they have impaired lung function, intrathoracic spread of tumour, or distant metastases. Of the remaining patients who appear to have technically operable lesions, at least two-thirds will present with distant metastases or a local recurrence within five years of apparently curative resection.

Though younger people have a lower perioperative mortality, their cancers may well be more aggressive and associated with shorter tumour doubling times. ${ }^{10}$ Older patients, for whom the risks of operation are greater, tend to have less aggressive tumours with longer doubling times; many of them might easily live for five years without any active intervention. We need to know much more about the natural history of untreated "operable" lung cancer. For the present, however, surgery still seems the best treatment for patients who are good operative risks. So long as predicting survival remains so unreliable it is hard to expect patients to provide informed consent, but they should fully realise that an operation is not a guarantee of a cure. Many of those hesitant or unwilling to take the risk may well survive for just as long without an operation.

1 McNeil, B J, Weichselbaum, R, and Pauker, S G, New England fournal of Medicine, 1978, 299, 1397.

2 Weiss, W, and Boucot, K. R, American Review of Respiratory Disease, 1977, 116, 827.

${ }^{3}$ Mountain, C F, in Lung Cancer: Natural History, Prognosis and Therapy, eds $L$ Israel and A P Chahinian, chap 6. New York, Academic Press, 1976.

4 Shields, T W, Surgery, Gynecology and Obstetrics, 1973, 136, 759.

5 Hilton, G, Thorax, 1960, 15, 17.

- Olsen, G N, et al, American Review of Respiratory Disease, 1975, 111, 379. 